The original can be found in:

http://link.springer.com/article/10.1007/s00107-013-0751-y

\title{
Comparison between heat treated sapwood and heartwood from Pinus pinaster
}

Bruno Esteves ${ }^{1 *}$, Lina Nunes ${ }^{2}$, Idalina Domingos ${ }^{1}$ and Helena Pereira ${ }^{3}$

${ }^{1}$ Polytechnic Institute of Viseu, Portugal and Centre for the Study of Education, Technologies and Health (CI\&DETS);

${ }^{2}$ National Laboratory for Civil Engineering (LNEC), Lisbon, Portugal Structures Department. Timber Structures Division and Azorean Biodiversity Group (CITA-

A) and Platform for Enhancing Ecological Research and Sustainability (PEERS), Universidade dos Açores, Terceira, Açores, Portugal;

${ }^{3}$ School of Agriculture, Technical University of Lisbon, Portugal. Forest Research Centre (CEF);

email: bruno@demad.estv.ipv.pt

Fax: 0351232424651

Phone: 0351-232480645 


\section{Abstract}

Sapwood and heartwood samples of Pinus pinaster were treated in an oven at $190^{\circ} \mathrm{C}$ and $200^{\circ} \mathrm{C}$ for 2-6h. Dimensional stability, measured as Anti Shrinking Efficiency (ASE) between 0\% and 65\% relative humidity, durability against fungi, mechanical resistance (MOE and MOR), hardness and chemical composition were determined for treated and untreated sapwood and heartwood. Radial ASE reached 52\% for sapwood and 50\% for heartwood while tangential ASE reached 50\% and $40 \%$ respectively. MOE increased slightly at the beginning of the treatment decreasing afterwards. No significant differences were found between sapwood and heartwood. MOR decreased by $50 \%$ and $30 \%$ for sapwood and heartwood respectively. A significant increase in durability against Rhodonia placenta was found for both heartwood and sapwood at the higher temperature and for heartwood only at $190^{\circ}$ for $4 \mathrm{~h}$.

Keywords: Dimensional stability; durability; heartwood; heat treatment; mechanical properties; sapwood

\section{Introduction}

Thermal modification is a well known process to improve some of the most important wood properties. The main changes are the reduction of equilibrium moisture content, the increased dimensional stability (Esteves et al. 2006, Esteves et al. 2008a, Esteves et al. 2007a) and the increased resistance against fungi (Dirol and Guyonnet, 1993; Tjeerdsma et al 2002; Hakkou et al. 2006; Boostra et al 2007c). Due to the treatment there is also a darkening of wood (Esteves et al. 2007b) and a decrease of wettability (Pecina and Paprzycki 1988; Kamdem et al 2002; Pétrissans et al. 2003; Hakkou et al. 2005; Kocaefe et al. 2008). The main problem of this treatment is, however, the degradation of some mechanical properties, mainly bending strength (Kim et al 1998) but also compression strength parallel to grain, modulus of elasticity in bending, janka hardness, impact bending strength, and tension strength perpendicular to the grain decrease (Korkut et al. 2008).

Thermal modification is probably the most successful modification process at the moment, especially in some Nordic countries, probably due to its low cost in relation to chemical and impregnation modifications, which use significant amounts of chemicals that make the final product more expensive. The thermal modification processes that reached the marketing stage with greater or lesser success are: ThermoWood ${ }^{\circledR}$ in Finland (Viitaniemi et al 1997), Plato ${ }^{\circledR}$ in the Netherlands (Boonstra et al 1998), Perdure, developed in France and later sold to a company in Canada (Kocaefe et al. 2008), Rectification in France (Dirol and Guyonnet, 1993) and Oil Heat Treatment in Germany (Sailer et al 2000). Thermal 
modification is a treatment performed at elevated temperatures $\left(160-260{ }^{\circ} \mathrm{C}\right)$ during a short time in an environment free from, or with low oxygen content using steam (ThermoWood $®$, Plato ${ }^{\circledR}$ and Perdure), an inert gas (Rectification) or oil (OHT). The processes generally consist of three stages: heating, cooling and stabilizing. A more complete description of the processes can be found at Esteves and Pereira (2009).

It has been said that one of the major advantages of heat treatment is the possibility to be applied to all species and to both sapwood and heartwood which is not possible with wood impregnation based modifications. Nevertheless most papers on heat treatment focus only on sapwood and no treatment is made with heartwood samples. One exception is the work of Metsä-Kortelainen et al. (2006) that reported the water absorption of sapwood and heartwood of heat-treated Scots pine (Pinus sylvestris) and Norway spruce (Picea abies) at $170^{\circ} \mathrm{C}, 190^{\circ} \mathrm{C}, 210^{\circ} \mathrm{C}$ and $230^{\circ} \mathrm{C}$. These authors studied water absorption by a floating test and concluded that water absorption decreased for sapwood only with a treatment at $230^{\circ} \mathrm{C}$, the heat-treatment at temperatures of $170{ }^{\circ} \mathrm{C}, 190{ }^{\circ} \mathrm{C}$ and $210{ }^{\circ} \mathrm{C}$ increased the water absorption. In relation to heartwood heat-treated samples at $210{ }^{\circ} \mathrm{C}$ absorbed more water than heat-treated samples at $170{ }^{\circ} \mathrm{C}$ and $190{ }^{\circ} \mathrm{C}$. For spruce, water absorption decreased similarly for heat treated sapwood and heartwood. Metsä-Kortelainen et al. (2012) also studied the wettability of heat treated sapwood and heartwood of Pinus sylvestris and Picea abies by measuring the contact angle: generally wettability of pine sapwood was higher than that of pine heartwood and the water repellency of sapwood only increased for wood treated at $230^{\circ} \mathrm{C}$. For treatments at lower temperatures of 170 and $190^{\circ} \mathrm{C}$ the wettability increased for all samples except for pine heartwood. In fact the sample treated at $170^{\circ} \mathrm{C}$, was the most water-repellent material in the whole study. No significant differences were obtained for spruce sapwood and heartwood where wettability increased at lower temperatures, decreasing for wood treated at $230^{\circ} \mathrm{C}$.

The decay resistance of sapwood and heartwood of untreated and thermally modified Scots pine was reported by Boonstra et al. (2007): heartwood showed a higher resistance against brown rot (Coniophora puteana and Rhodonia placenta) and white rot (Coriolus versicolor). Metsä-Kortelainen and Viitanen (2009) also reported on the heat treated heartwood durability of Scots pine and 
Norway spruce and concluded that the treatment increased the durability of all the wood materials.

This paper intends to enlighten the differences between heat treated Pinus pinaster sapwood and heartwood, and to discuss the feasibility and the difficulties in treating heartwood samples.

\section{Experimental}

\section{Treatment}

The samples for the treatment were cut from two central boards of pine (Pinus pinaster Ait.) mature trees. Sapwood and heartwood were separated and the transition zone cut off. Three types of samples were prepared: cubic samples with approximately $40 \mathrm{~mm}$ edge with clear radial, tangential and transversal faces (3 samples for each temperature/time treatment+ 4 untreated samples) totalizing 22 samples, for dimensional stability; samples with 340 × $20 \times 20 \mathrm{~mm}^{3}$ (axial x radial $\mathrm{x}$ tangential) for static bending ( 4 samples for each treatment +4 untreated

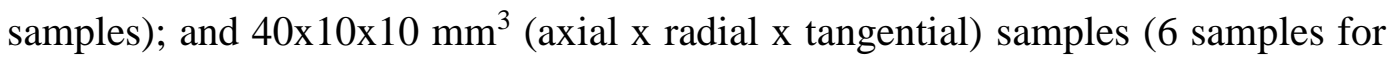
each treatment) for biodegradation tests. All the samples were kept in an incubator at $65 \pm 5 \%$ relative humidity and $20 \pm 1^{\circ} \mathrm{C}$ before the treatment.

The heat treatment was made at atmospheric pressure inside an oven for 2 to 6 hours, and at $190{ }^{\circ} \mathrm{C}$ and $200^{\circ} \mathrm{C}$. The warm-up period was about one hour to reach the desired treatment temperature, which was kept constant at $\pm 5^{\circ} \mathrm{C}$. At the end of each treatment, the samples were cooled in a dry environment and weighted. Weight loss was determined in relation to dry wood.

\section{Equilibrium moisture and Dimensional stability}

After the treatment, the cubic samples for dimensional stability (treated and untreated) were kept in an oven at $100^{\circ} \mathrm{C}$ overnight, cooled in a dry environment, weighed and measured in radial, tangential and longitudinal directions. After that, the samples were kept in an oven at $65 \pm 5 \%$ relative humidity (RH) and $20 \pm 1{ }^{\circ} \mathrm{C}$ for at least 5 weeks or until stabilization was achieved. Afterwards, the samples were weighed and measured in radial, tangential and longitudinal directions. Equilibrium moisture content was determined for $65 \% \mathrm{RH}$ as the mass difference between $65 \%$ and dry state. Dimensional stability was determined by the Anti-Shrinking Efficiency (ASE) 
method used by Stamm et al. (1946) and described in Esteves et al (2007a, b; 2008a). This method gives the shrinking difference between treated and untreated samples calculated in percent, and determined between $65 \%$ RH and the dry state.

\section{Bending strength}

Bending strength and modulus of elasticity were determined by a three point bending device. Measurements were made using a constant velocity of 40 kgf/min. MOE and bending strength were determined according to NP 619:

$\operatorname{MOE}\left(\mathrm{N} / \mathrm{mm}^{2}\right)=\frac{\Delta F^{*} L^{3}}{\Delta x * 4 * b^{*} h^{3}}$

Bending strength $(\mathrm{MPa})=\frac{3 F_{\text {máx }} * L}{2 * b^{*} h^{10 / 6}}$

where $\mathrm{F}_{\text {máx }}$ is the load on rupture in $\mathrm{N}, \frac{\Delta F}{\Delta x}$ is the slope of the elastic zone in $\mathrm{N} / \mathrm{mm}, \mathrm{L}$ is the arm length, $\mathrm{h}$ the height and $\mathrm{b}$ the width all expressed in $\mathrm{mm}$.

\section{Durability}

A brown rot fungi, Rhodonia placenta (Fr.) Lars et Lomb. was used to evaluate the resistance to decay by the method described in CEN/TS 15083-1 (2005) though with specimens of smaller dimensions $(15 \mathrm{~mm} \times 25 \mathrm{~mm} \times 50 \mathrm{~mm})$. The number of test specimens was 4 to 6 replicates per variable tested, and the exposure period was 8 weeks.

\section{Janka Hardness}

Janka hardness was measured according to ISO 3350 (1975) standard with minor changes. The force used was the force required to penetrate a steel ball of 11.28 $\mathrm{mm}$ in wood up to a quarter of its diameter $(2.82 \mathrm{~mm})$, instead of half as mentioned in the standard due to the softness of Pinus pinaster wood.

\section{Extractives}

Samples of treated sapwood and heartwood with weight loss around 3\% and $4.5 \%$ were chosen for the determination of the extractive content since the weight loss necessary to improve significantly the wood properties is generally considered as 3\% (Boonstra 2008). All samples (including the untreated controls) 
were ground in a Retsch SMI mill and a Thomas mill and then sieved with a Retsch AS200 basic sieve for $20 \mathrm{~min}$ at a $50 \mathrm{rpm}$ speed. The $40-60$ mesh fraction was used for chemical analysis following Tappi T 264 cm-97.

The extractive content was determined by successive Soxhlet extraction of about $3 \mathrm{~g}$ of each sample with $150 \mathrm{ml}$ of dichloromethane (DCM), ethanol, and water during $10 \mathrm{~h}$ for DCM and $20 \mathrm{~h}$ for ethanol and water. The extracted solution was evaporated, dried in an oven at $40^{\circ} \mathrm{C}$ overnight, followed by $1 \mathrm{~h}$ drying at $100^{\circ} \mathrm{C}$, except for water where the extract was dried directly in an oven at $100^{\circ} \mathrm{C}$. The percentage of extractives in each solvent was determined gravimetrically in relation to initial dry mass according to Tappi 204 Mac-88.

\section{Klason Lignin}

For the determination of insoluble Klason lignin $350 \mathrm{mg}$ of each sample were weighed and placed in a $100 \mathrm{ml}$ goblet to which $3 \mathrm{ml}$ of iced sulphuric acid at $72 \%$ were added and the goblet placed in a thermostatic bath at $30{ }^{\circ} \mathrm{C}$ for one hour, stirring the mixture with a glass rod every 10 minutes. Afterwards, $84 \mathrm{ml}$ of distilled water were added and the mixture transferred to a $100 \mathrm{ml}$ Schott flask. The flasks were then placed in an autoclave with water at the bottom. The samples remained in the autoclave for one hour at a temperature of $120^{\circ} \mathrm{C}$ and were then removed and cooled with ice. The samples were filtered with a pre weighed No 4 crucible and washed with tepid water. The crucibles containing the lignin were placed in an oven at $60^{\circ} \mathrm{C}$ overnight, followed by one hour at $100^{\circ} \mathrm{C}$, cooled down and weighed. Lignin was determined in relation to initial dry wood. 


\section{Results and discussion}

\section{Treatment}

Weight loss increased with the treatment intensity for both sapwood and heartwood. At the earlier stages, heartwood seems to lose more weight than sapwood but as the treatment continues weight loss of sapwood increases reaching 10.7\% against $5.1 \%$ for heartwood at the same treating conditions (Fig 1). Heartwood is more resistant to heat since sapwood weight loss is considerably higher than that of heartwood for longer treatments.

At the beginning of the treatment, most of the weight loss is probably due to wood resin that travels to the surface of the samples and then leaves the wood, as reported earlier (Esteves et al. 2008b, Esteves et al. 2011). Heartwood has much higher resin content and therefore the weight loss is higher at the beginning. When most of the resin was thermally degraded or left the wood, weight loss is due to the degradation of polysaccharides and lignin, starting by hemicelluloses followed by cellulose and lignin (Esteves et al. 2008b, Esteves et al. 2011). This is in accordance with the initial decrease of DCM extractives that can be observed in Figure 2.

At about 3\% weight loss (Fig 2), total extractives increased for sapwood and decreased for heartwood. The main reason might be that in heartwood the evaporation of volatile compounds from wood resin is higher than the amount of new extractable compounds formed by hemicelluloses degradation. Since sapwood has lower resin content, the amount of new compounds is higher than the loss of original extractable compounds. Even thought total extractives increase for heat treated sapwood, dichloromethane extractives decrease. This decrease means that the amount of non-polar compounds like fat and resin acids is lower for treated wood. The observed increase is due to the ethanol and largely to water extracts.

These results are in accordance to the results presented by Esteves et al. (2008b, 2011) who attributed the increase in ethanol and water extracts to sugars, mainly anhydrosugars resulting from hemicelluloses degradation.

In relation to heartwood the results show that the amount of extractives is very variable due to the high resin content. The initial decrease of DCM extractives is followed by an increase while water extracts decrease. Ethanol 
extractives however increase throughout the treatment. One of the main reasons for the different behaviour between heartwood and sapwood extractives might be the higher heartwood resistance to heat. If heartwood degradation is lower than that of sapwood (Fig 1), it is expectable to have less extractable polar compounds in heartwood since ethanol and water extractives increase due to polysaccharides and lignin degradation.

Klason lignin percentage increased for sapwood with the increase in treatment intensity. For heartwood, even thought lignin content is higher for treated wood the increase is smaller and somewhat inconstant (Table 1)

The treatment induced colour changes on sapwood and on heartwood that became darker as the treatment proceeded. This is a well known fact reported by several authors (Mitsui et al 2001; Esteves et al. 2007b). Visually, no significant differences between heartwood and sapwood were observed (Fig 3). One of the main differences between treated sapwood and heartwood surface was the presence of resin on the surface of the heartwood treated samples. Even though there was also some resin on the surface of sapwood samples (Fig 3), the surface appeared smoother and without pitch. These stains might give wood an aesthetic look which would depreciate is value. To eliminate or at least mitigate this problem, the treatment may be made at smaller temperatures but during longer time. Nevertheless if the boards are processed after the treatment it will be possible to remove the stains from the surface.

\section{Equilibrium moisture}

Equilibrium moisture content (EMC) for untreated wood was about $12 \%$ for both sapwood and heartwood at $65 \%$ relative humidity (Fig 4). EMC decreased rapidly with the treatment until about $3 \%$ weight loss, decreasing then much more slowly. The minimum EMC was about $7.0 \%$ for sapwood and $7.4 \%$ for heartwood, corresponding to $42 \%$ and $39 \%$ improvement in relation to untreated wood. No significant differences were obtained between sapwood and heartwood although at the same weight loss equilibrium moisture content decreased more for sapwood. Similar results were reported by Metsä-Kortelainen(2011). According to this author equilibrium moisture content for spruce decreased from $10.6 \%$ to $5.9 \%$ and from $10.3 \%$ to $5.3 \%$, and for Scots pine from $10.1 \%$ to $5.4 \%$ and $9.8 \%$ to 
4.7\% for sapwood and heartwood respectively. In both cases there were no significant differences between sapwood and heartwood.

\section{Dimensional stability}

Dimensional stability measured as ASE is presented in Figure 5 in radial and tangential directions. Radial ASE increased with the increasing intensity of the treatment with a higher slope in the beginning of the treatment reaching about $52 \%$ for sapwood and 50\% for heartwood. No differences between heartwood and sapwood could be determined. Tangential ASE increased similarly to radial ASE reaching about $50 \%$ for sapwood and $40 \%$ for heartwood, respectively. At the same weight loss, sapwood seemed to have a higher ASE in the tangential direction (Fig 5, right). For the same treatment conditions, the dimensional stability had a similar improvement for softer treatments, but for wood treated at $200^{\circ} \mathrm{C}$ for $6 \mathrm{~h}$ the improvement was higher for sapwood than for heartwood. This was to be expected since for longer treatments heartwood proved to be more heat resistant (Fig 1). With less degradation there is also less improvement in dimensional stability.

\section{Mechanical properties}

MOE increased slightly at the beginning of treatment, decreasing afterwards. No significant differences were found between sapwood and heartwood (Fig 6). MOR decreased reaching almost a 50\% and 30\% decrease for sapwood and heartwood respectively. Similar results were earlier reported for sapwood (Esteves et al. 2006). Although the decrease in MOR was smaller for heartwood, at the same weight loss there were no significant differences between heartwood and sapwood. MOR decreased almost linearly in sapwood presenting a coefficient of determination of $\mathrm{R}^{2}=0.9909$. The MOR values for heartwood were more scattered probably due to the high variation on extractive content due to the accumulation of resin in some parts of the samples which might have influenced the bending strength determination. This high decrease in the mechanical strength makes this wood unsuitable for structural applications, nevertheless a decrease of $30 \%$ for wood with about $3 \%$ weight loss is acceptable for most applications like cladding, sound barriers or decking. 


\section{Janka Hardness}

Figure 7 presents the hardness variation for heat treated sapwood and heartwood in relation to weight loss. In the initial treatment stage, there appears to be a slight increase in hardness, followed by a decrease for higher weight losses. The maximum decrease in relation to untreated wood reached $20 \%$ for sapwood and $13 \%$ for heartwood. Similarly to bending strength, hardness of heartwood samples presented a higher dispersion which in this case can be justified due to the resin content near and on the wood surface that increases hardness.

These results are in accordance with the results presented by Poncsák et al. (2006) who reported a slight hardness increase followed by a decrease with increasing holding time for heat treated birch. The same initial increase was mentioned by Sundqvist et al. (2006) and attributed to condensation reaction in lignin and cellulose. However this increase was not found by Korkut et al. (2008) who studied heat-treated Scots pine wood and concluded that Janka hardness decreased with the increase in temperature and time of treatment. The same was reported by Korkut and Hiziroglu (2009) for hazelnut wood with a 60\% reduction for Janka hardness.

\section{Durability}

Durability against Rhodonia placenta was evaluated by a mini-block method for sapwood and heartwood samples treated at $190^{\circ} \mathrm{C}$ and $200^{\circ} \mathrm{C}$ for $2 \mathrm{~h}$ and $4 \mathrm{~h}$. The results showed a significant decrease of weight loss with the temperature used and with the time of treatment (Figure 8). A significant increase in durability was found for both heartwood and sapwood at the higher temperature and for heartwood only at $190^{\circ}$ for $4 \mathrm{~h}$. The pattern of mass decrease was similar for sapwood and heartwood but the highest level of protection against $R$. placenta was achieved for sapwood treated at $200^{\circ} \mathrm{C}$ for 4 hours. At the same treatment conditions weight loss due to thermal treatment is higher for sapwood, as seen on Figure 1 . Only at $200^{\circ} \mathrm{C} / 4 \mathrm{~h}$ mass loss was lower than $5 \%$ but all treated samples had lower mass loss than untreated meaning that some protection could be achieved. 
In accordance with Metsä-Kortelainen and Viitanen (2009) heat treatment increased significantly the decay resistance of pine and spruce heartwood and sapwood samples. However, heat treatment had to be done at temperatures higher than $230^{\circ} \mathrm{C}$ to reach durability class 1 or 2 against soft-rot. The differences between sapwood and heartwood were more significant for pine than for spruce. Boonstra et al. (2007) treated Scots pine sapwood and heartwood and concluded differently that heartwood showed a higher resistance against Coniophora puteana, Rhodonia placenta and the white rot fungus Coriolus versicolor.

\section{Conclusions}

1. The heat treatment is equally efficient for pine sapwood and heartwood when comparing at the same weight loss. Since temperature and treatment time influenced differently on heartwood and sapwood i.e. on weight loss, the extent of improvements varied between sapwood and heartwood with the same treatment conditions i.e. the improvement was higher for sapwood.

2. Radial ASE reached $52 \%$ for sapwood and $50 \%$ for heartwood while tangential ASE reached $50 \%$ and $40 \%$ respectively.

3. MOE increased slightly at the beginning of the treatment decreasing afterwards. No significant differences were found between sapwood and heartwood.

4. MOR decreased for both heartwood and sapwood, reaching almost a 50\% and $30 \%$ decrease for sapwood and heartwood respectively.

5. A significant increase in durability against Rhodonia placenta was found for both heartwood and sapwood at the higher temperature, and for heartwood only at $190^{\circ}$ for $4 \mathrm{~h}$.

6. The presence of resin in the surface of heartwood samples may lead to some aesthetic problems.

Acknowledgments- The authors are grateful for the support of the Portuguese Foundation for Science and Technology(FCT) and Center for Studies in Education, Technologies and Health essential for the accomplishment of this work. The Forest Research Centre is funded by FCT. 


\section{References}

Ayadi, N., Lejeune, F., Charrier, F., Charrier, B., and Merlin, A. (2003). "Color stability of heattreated wood during artificial weathering," Holz Roh-Werkst. 61, 221-226.

Boonstra, M. (2008). "A two-stage thermal modification of wood" Ph.D. Thesis in Applied Biological Sciences: Soil and Forest management. Henry Poincaré University-Nancy, France.

Boonstra, M., Tjeerdsma, B. and Groeneveld, H. (1998). "Thermal Modification of Non-Durable Wood Species. 1. The Plato technology: thermal modification of wood," International Research Group Wood Pro, Section 4 - Processes. 29 Annual Meeting, Maastricht, June $14-19,13 \mathrm{p}$.

Boonstra, M., Van Acker, J, Kegel, E. and Stevens, M. (2007). “Optimisation of a two-stage heat treatment process. Durability aspects. Wood Sci. Technol.41(1):31-57.

CEN/TS 15083-1 (2005) Durability of wood and wood-based products. Determination of the natural durability of solid wood against wood-destroying fungi, Test methods. Part 1: Basidiomycetes. CEN, Brussels.

Dirol, D., and Guyonnet, R. (1993). "Durability by rectification process," In: International Research Group Wood Pro, Section 4-Processes, N IRG/WP 93-40015

Esteves, B., Domingos, I. and Pereira, H. (2007a) "Improvement of technological quality of eucalypt wood by heat treatment in air at 170-200 degrees" C. For. Prod. J 57(1-2), 4752.

Esteves, B., Graça, J. and Pereira, H. (2008b) "Extractive composition and summative chemical analysis of thermally treated eucalypt wood". Holzforschung 62(3), 344-351.

Esteves, B., Marques, A.V., Domingos, I. and Pereira, H. (2006) "Influence of steam heating on the properties of pine (Pinus pinaster) and eucalypt (Eucalyptus globulus) wood". Wood Sci. Technol 41, 193-207.

Esteves, B., Velez Marques, A., Domingos, I. and Pereira, H. (2007b) "Heat-induced colour changes of pine (Pinus pinaster) and eucalypt (Eucalyptus globulus) wood". Wood Sci. Technol 42(5), 369-384.

Esteves, B., Videira, R. and Pereira, H. (2011) "Chemistry and ecotoxicity of heat-treated pine wood extractives". Wood Sci. Technol.

Esteves, B.M. and Pereira, H. (2009) "Wood modification by heat treatment: A review". BioResources 4(1), 340-404.

Esteves, B.M., Domingos, I.J. and Pereira, H. (2008a) "Pine wood modification by heat treatment in air". BioResources 3(1), 142-154.

Hakkou, M., Pétrissans, M., El Bakali, I., Gérardin, P. and Zoulalian, A. (2005) "Wettability changes and mass loss during heat treatment of wood". Holzforschung 59(1), 35-37.

Hakkou, M., Pétrissans, M., El Bakali, I., Gérardin, P. and Zoulalian, A. (2003). "Evolution of wood hydrophobic properties during heat treatment," In: Abstracts of the First European Conference on Wood Modification, Ghent, Belgium.

Hakkou, M., Pétrissans, M., Gérardin, P. and Zoulalian, A. (2006) "Investigations of the reasons for fungal durability of heat-treated beech wood". Polymer Degrad Stab 91(2), 393-397.

ISO 3350- Wood -1975 - Determination of static hardness.

Kamdem, D., Pizzi, A. and Jermannaud, A. (2002). "Durability of heat-treated wood," Holz RohWerkst. 60, 1-6.

Kim, G., Yun, K. and Kim, J. (1998). "Effect of heat treatment on the decay resistance and the bending properties of radiata pine sapwood," Material und Organismen 32 (2), 101-108.

Kocaefe, D., Poncsak, S., Dore, G., and Younsi, R. (2008b). "Effect of heat treatment on the wettability of white ash and soft maple by water" Holz Roh-Werkst. 66, 355-361.

Korkut, S. and Hiziroglu, S. (2009) "Effect of heat treatment on mechanical properties of hazelnut wood (Corylus colurna)". Materials \& Design 30(5), 1853-1858.

Korkut, S., Akgü, M. and Dündar, T. (2008). "The effects of heat treatment on some technological properties of Scots pine (Pinus sylvestris L.) wood," Bioresour. Technol. 99, 1861-1868.

Metsä-Kortelainen, S. (2011) "Differences between sapwood and heartwood of thermally modified Norway spruce (Picea abies) and Scots pine (Pinus sylvestris) under water and decay exposure" VTT, Espoo. VTT Publications:771.

Metsä-Kortelainen, S. and Viitanen, H. (2009) "Decay resistance of sapwood and heartwood of untreated and thermally modified Scots pine and Norway spruce compared with some other wood species". Wood Material Science \& Engineering 4(3-4), 105-114. 
Metsä-Kortelainen, S. and Viitanen, H. (2012). "Wettability of sapwood and heartwood of thermally modified Norway spruce and Scots pine". European Journal of Wood and Wood Products 70:135-139.

Metsä-Kortelainen, S., Antikainen, T. and Viitaniemi, P. (2006). "The water absorption of sapwood and heartwood of Scots pine and Norway spruce heat-treated at $170^{\circ} \mathrm{C}, 190^{\circ} \mathrm{C}$, $210^{\circ} \mathrm{C}$ and $230^{\circ} \mathrm{C}, "$ Holz Roh-Werkst. 64(3),192-197.

Mitsui, K., Takada, H., Sugiyama, M. and Hasegawa, R. (2001). "Changes in the properties of light-irradiated wood with heat treatment: Part 1 Effect of treatment conditions on the change in color," Holzforschung, 55, 601-605.

NP 619 (1973)- Ensaio de flexão estática de madeiras

Pecina, H. and Paprzycki, O. (1988). "Wechselbeziehungen zwischen der temperaturbehandlung des holzes und seiner benetzbarkeit," Holz. Holzverwert 40(1), 5-8.

Pétrissans, M., Philippe, G., El Bakali, I. and Serraj, M. (2003). "Wettability of heat-treated Wood," Holzforschung 57, 301-307.

Poncsák, S., Kocaefe, D., Bouazara, M. and Pichette, A. (2006) "Effect of high temperature treatment on the mechanical properties of birch (Betula papyrifera). Wood Sci. Technol 40(8), 647-663.

Sailer, M., Rapp, A. and Leithoff, H. (2000). "Improved resistance of Scots pine and spruce by application of an oil-heat treatment," In: International Research Group Wood Pre, Section 4-Processes, $N^{\circ}$ IRG/WP 00-40162.

Stamm, A.J., Burr, H.K. and Kline, A.A. (1946) "Staybwood-heat-stabilized wood." Industrial \& Engineering Chemistry 38(6), 630-634.

Sundqvist, B., Karlsson, O. and Westermark, U. (2006) "Determination of formic-acid and acetic acid concentrations formed during hydrothermal treatment of birch wood and its relation to colour, strength and hardness". Wood Sci. Technol 40(7), 549-561.

Tappi 204 Mac-88 - Solvent Extractives of Wood and Pulp. Technical Association of the Pulp and Paper Industry.

Tappi T 264 cm-97- Peparation of Wood for Chemical Analysis. Technical Association of the Pulp and Paper Industry / 07-Apr-1997

Tjeerdsma, B., Stevens, M., Militz, H. and Van Acker, J. (2002). "Effect of process conditions on moisture content and decay resistance of hydro-thermally treated wood," Holz. Holzverwert.5:94-99

Viitaniemi, P., Jämsä, S. and Viitanen, H. (1997). "Method for improving biodegradation resistance and dimensional stability of cellulosic products," United States Patent $\mathrm{N}^{\mathrm{o}}$ 5678324 (US005678324).

Fig.1. Weight loss of heartwood and sapwood samples due to heat treatment.

Fig.2. Extractive content of untreated and heat treated sapwood and heartwood.

Fig.3. Color changes for heat treated sapwood (bottom) and heartwood (top)

Fig.4. Equilibrium moisture content vs weight loss due to heat treatment of sapwood and heartwood samples.

Fig.5. Dimensional stability of heat treated sapwood and heartwood measured as ASE in the radial and tangential directions at $65 \%$ Relative humidity

Fig.6. MOE and MOR vs weight loss for heat treated sapwood and heartwood.

Fig.7. Janka Hardness vs weight loss for heat treated sapwood and heartwood.

Fig.8. Durability against Rhodonia placenta.

Table 1-Klason lignin for untreated and heat treated sapwood and heartwood. 


\begin{tabular}{|l|c|c|c|c|c|c|}
\hline & \multicolumn{3}{|c|}{ Sapwood } & \multicolumn{3}{c|}{ Heartwood } \\
\hline Weight loss (\%) & 0,0 & 3,0 & 4,5 & 0,0 & 3,0 & 4,5 \\
\hline Lignin (\% od mass) & 24,12 & 25,30 & 26,74 & 23,20 & 25,20 & 24,15 \\
\hline
\end{tabular}

